\title{
The Negotiated Order and Electronic Patient Records: A sociomaterial perspective ${ }^{1}$
}

\author{
Lucas D Introna , Niall Hayes and Zaina Al-Hejin - Lancaster University
}

\section{ABSTRACT}

In this paper, we consider how the notion of the negotiated order can be reinterpreted by drawing on ideas from sociomateriality. We argue that the negotiated order is an ongoing accomplishment in which a heterogeneous set of situated sociomaterial practices (or actors) are implicated. To do this we draw upon an in-depth study of the use of a computerised physician order entry system (CPOE) in a hospital in Saudi Arabia. We explore how a CPOE, as a new sociomaterial actor, performatively repositions the actors involved and hence offers the conditions of possibility for medical work practices to be renegotiated. We show that it is often contingent, mundane, situated sociomaterial practices that enact the conditions under which the negotiated order becomes re-established in terms of division of labour, legitimacy, collaboration, and social capital. We argue that as the social and material are co-constitutive, or intra-actional, it makes more sense to talk about the negotiated intra-actional order rather than the negotiated order. Importantly, such a change in conceptual vocabulary reveals the empirical and ontological issues at stake; essential for a more nuanced understanding of change/becoming.

\section{Keywords}

Negotiated order; sociomateriality; social capital; electronic patient records; computerised physician order entry system; sociomaterial capital

\section{INTRODUCTION}

In this paper, we consider how the negotiated order of medical practice becomes disrupted and renegotiated with the introduction of a new more-than-human actor: a computerised physician order entry (CPOE) module of the Electronic Patient Record (EPR) system. The CPOE module requires

\footnotetext{
${ }^{1}$ Accepted and forthcoming in the Journal of Information Technology.
} 
physicians to enter their orders for prescriptions, dosages, tests etc. into an information system electronically (Li et al., 2014; Tsai et al., 2017). The orders of physicians are then actioned by other healthcare professionals such as nurses, pharmacists and radiologists. CPOE is claimed to lead to a safer, more streamlined and efficient way to provide care to patients (Escobar-Rodríguez and RomeroAlonso, 2014; Hsu et al., 2015; Kaganer et al., 2010). CPOE provides for alerts to signal when interventions are needed or incompatible treatments have been ordered (Escobar-Rodríguez and Romero-Alonso, 2014). In our case, we studied the introduction of CPOE in a hospital in Saudi Arabia. In attending to the disruption of the negotiated order in the hospital, we focus on how the coordination of work and division of labour between medical professionals relied upon a paper-based sticker to supplement the EPR, and second, the implications that arose from the reluctance by the physicians to engage with the CPOE's functionality.

The notion of the negotiated order has been influential in making sense of how situated interactional relationships between people 'structure' or arrange work practices. The sociologist Erving Goffman (1983) talked about this situated 'structure' (or structuring) as an interaction order. For him, this ordering of interactions is conditioned by many normatively governed rules of the game or scripts, which are enacted repeatedly, and largely consistently, to become routine. These rules of the game are normally both medium and outcome of implicit or explicit and situated negotiations between the actors involved; what Strauss (1978) calls the negotiated order. He argued and demonstrated, in the professional context of a hospital, that although there were normally formal structures, roles, policies, protocols, etc., these were often ignored, reinterpreted, and mobilised as the different actors (nurses, doctors, patients, managers, etc.) tried to secure their own interests in the flow of daily situated practice (Svensson, 1996). Relevant to the focus of this paper, Stephen Barley (1986) demonstrated in his seminal paper that the introduction of new technology into medical work (radiography in his case) disrupts the negotiated order and creates opportunities for renegotiation; especially in terms of the reestablishment of professional boundaries. This paper focuses on how the implementation of new information technology is implicated in the (re)negotiated order. We attend specifically to the division of labour in the ongoing negotiation of professional boundaries, and the role of non-human actors that is, the EPR, the CPOE module, and paper-based medical records - in such renegotiations.

A review of the current work on the negotiated order reveals that this literature has a very humancentric view of how these renegotiations happen and how the various actors draw on their resources and capital to secure their interests. What has not been attended to sufficiently is how the negotiated order may be understood if we expand the landscape of actors to the more-than-human. Recently we 
have had the emergence of what has become known as sociomateriality (Orlikowski and Scott (2008, 2013). In this work, the social and the material are co-constitutive, or intra-actional, which leads us to propose that including the more-than-human requires us to reconsider our existing understandings of the relationally enacted (re)negotiated order, and how it is accomplished in daily work practice (see also Hultin and Introna, 2018; Introna, 2013).

The paper is structured as follows. The next section reviews literatures that have considered the negotiated order and then CPOE systems. Section 3 describes our ontological underpinnings; that is, sociomateriality. Section 4 outlines our empirical context and methods, while section 5 provides an analysis of the case through the lens of sociomateriality, and specifically examines how the negotiated order in our hospital is reconstituted through the introduction of CPOE. Section 6 offers a discussion of the various ways in which the new sociomaterial actors disrupt the negotiated order, and section seven offers some brief conclusions.

\section{NEGOTIATED ORDER AND CPOE}

The negotiated order. The notion of negotiated order highlights how the micro-practices of daily work are ambiguous, contested, and in need of ongoing negotiation to 'make it work' (Strauss, 1978). This entails an ongoing and situated process of 'working things out'; a process through which working arrangements are established, kept going, and revised, repeatedly (Strauss and Corbin, 1998: 73). Strauss (1978) summarises the negotiated order as follows:

The negotiated order on any given day could be conceived of as the sum total of the organization's rules and policies, along with whatever agreements, understandings, pacts, contracts, and other working arrangements currently [operate]. These include agreements at every level of the organization, of every clique and coalition, and include covert as well as overt agreements. (pp. 5-6)

Strauss' notion of negotiated order highlights that the most important ordering processes of ongoing work practices are those that are agreed implicitly or explicitly through situated and ongoing relational interaction. In other words, social order (or structure) is situated, relational, and in need of ongoing re-enactment. Thus, the seemingly interactional orderliness of work arrangements emerges from, and constrains, ongoing negotiations. Although actors may occupy social positions (such as professional roles) and have certain dispositions (or affordances, in the case of technologies), they are not moulded by them entirely. As Mouzelis (1992: 127) suggests, with reference to Goffman's work, "the specificity of the interaction order consists of the fact that norms and rules - whether they impinge on actors' 
games via social roles and positions or via dispositions - never can eliminate a space of interactive indeterminacy or uncertainty." This interactive indeterminacy and uncertainty requires that actors 'think on their feet' in order to "devise strategies and counterstrategies that are shaped partly by the logic of social positions and dispositions, and partly by the logic of the interaction situation itself".

The more-than-human actor. Our paper focuses on how any new more-than-human actor entering the field, the CPOE in our case, might disrupt the negotiated order. Consequently, the remainder of this section will consider the literature that has examined CPOE and medical care practices. CPOE has been criticised for disrupting collaboration across professional boundaries due to the individualised flow of medical work (Menon et al., 2016). Individualising responsibility is claimed to be detrimental to knowledge sharing between physicians and other health care professionals (Menon et al., 2016; Wears and Berg, 2005). As Aarts et al. (2007: s5) highlight, this is because "knowledge about the patient's illness and treatment is distributed among the participants." Entering orders in isolation from other healthcare professionals reduces opportunities for discussion and joint decision-making about patients. Order entry is claimed to lead to an increased workload for doctors which impinges on the time they have to spend with patients (Aarts et al., 2007; Beuscart-Zéphir et al., 2005). Indeed, CPOE is claimed to take physicians about twice as long as paper ordering, which leads to delays in treatment (Van Der Sijs et al., 2011; Halbesleben et al., 2010; Warholak and Rupp, 2009; Debono et al., 2013; Rack et al., 2012). Some have claimed that that CPOE can be dangerous to patients as decisions may be made without sufficient consultation with and between healthcare professionals such as junior doctors and nurses (Aarts et al., 2007; Beuscart-Zéphir et al., 2005; Petrakaki et al., 2014). Moreover, Petrakaki et al (2014) found that healthcare staff are cautious with what they record, so that they cannot be subsequently blamed for any negative outcomes or mistakes, and/or to pass the potential blame onto other healthcare professionals (Saginur et al., 2008)

Studies have also highlighted that some CPOE practices violate drug administration procedures and staff responsibilities (Alter, 2014; Zhou et al., 2011). For example, Zhou et al.'s (2011) study found that rather than requiring a nurse to leave a bedside each time they needed to review the orders on the CPOE, a hospital ward had hired an administrator to convey the orders to nurses, sometimes via a pager. Cheng et al (Cheng et al., 2003: 153) highlighted that when interventions were urgent, such as in an intensive care unit, "orders begin to be executed before all verification steps (in the CPOE) are complete." They highlighted that in such cases, the fact that it is not possible for the different clinicians "to be at their geographical printing stations to receive the order introduces delays in the process." 
Others have found that medical conferences still occur yet remain invisible to the CPOE system (Cheng et al., 2003; Fitzpatrick and Ellingsen, 2013; Zhou et al., 2011)

A recurring and relevant theme in the CPOE literature has been the role of paper-based workarounds employed in collaboration between healthcare professionals (Flanagan et al., 2013). Menon et al.'s (2016) study highlighted that physicians and nurses often print out and annotate the CPOE records to aid face-to-face collaboration between healthcare professionals and with patients. They found that healthcare staff frequently transfer CPOE information, test results, reminders and prescriptions to sticky notes and paper lists, and use alternative technologies such as an electronic calendar and word processing files, alongside paper lists, in conjunction with the CPOE system when they treat patients (Berg, 1996; Cheng et al., 2003; Christensen, 2016; Menon et al., 2016).

What emerges from the literature is that the implementation of CPOE often disrupts medical work practices (especially the professional division of labour) and that medical staff often must renegotiate new practices-often with workarounds (Alter, 2014) in, through, or around CPOE itself-to 'keep things moving along' and to ensure ongoing patient safety. The latter was something CPOE was supposed to improve. How such situated renegotiations happen, and who is implicated, really matters if we want to understand the transformation of medical work practices in a world where the CPOE already operates, quite decisively, as the literature and our research suggests. To understand such mattering we need to take the more-than-human more seriously, as has been suggested by sociomaterial scholars.

\section{SOCIOMATERIALITY: FROM INTERACTION ORDERS TO INTRA-ACTION ORDERS}

This paper argues that to understand fully how the introduction of a new CPOE transforms medical work, in addition to the notion of the negotiated order, we need to adopt a sociomaterial perspective. Such a move accomplishes at least two things: (1) it decentres human action to include more-than human agency, and (2) it introduces a performative understanding of action and actors.

Latour (1992) has argued for the return of the 'missing masses' to our sociological accounts. He argues that that which we consider 'the social' is in fact an ongoing sociomaterial accomplishment that includes a wide range of human and non-human actors. It is a heterogeneous networking (not network) of actions flowing from everywhere and nowhere, accomplishing the seeming obviousness of everyday social life; be it work-life, family-life, political-life etc. What he did not attend to, at least not explicitly, is the performative nature of such networking (although one can argue that it is implicitly 
there in his work). A more explicit account of performativity is offered by Karin Barad, with her notion of intra-action-which has been drawn upon by a variety of organisation studies and IS researchers (See for example: Barrett et al., 2012; Cecez-Kecmanovic et al., 2014; Introna and Hayes, 2011; Scott and Orlikowski, 2014). In her 'relational ontology', or ontology of becoming, Barad (2003) shifts the focus from humans and non-humans and how their interactional relationships develop, to 'agential intra-action' in which actors and actions (or practices) are produced intra-actively. Interactions, in the interactional and negotiated order, assume that entities (human and non-human) exist as such, and then interact. In contrast, intra-actions are, as Barad (2003: 815) suggests, "ontologically primitive relations - relations without pre-existing relata." This means that all assumed beings or entities (human and non-human alike) do not exist, as more or less complete entities, prior to intra-actions. They are open-ended beings (or becomings) that are continually (re)enacted through their relational intra-action with other assumed entities, which are not fixed but works-in-progress: continually becoming, differently. This helps us to recast the negotiated order as being better understood as negotiated intra-actional order.

The concept of a negotiated intra-actional order moves us away from assuming that actors (nurses, doctors, CPOE, paper medical record, etc.) interact as fully constituted entities. Rather they are enacted through their ongoing intra-actions. The doctor intra-acting with the paper medical record (and simultaneously with all of the other actors) is fundamentally a different doctor to the doctor intra-acting with the CPOE. The doctors in these intra-actions are differently constituted such that different types and degrees of actions become possible for them, and others become less or even not possible. The same applies to nurses, medical records, the CPOE, and more besides. There exists something (a doctor) prior to every intra-action, but that something is always a work-in-progress, a becoming, which is subject to significant transformations with every intra-action, however minor or significant. We draw on this notion of the negotiated intra-actional order to understand how a new actor, the CPOE, disrupted the medical work practices, professional identities and capital of doctors and nurses.

\section{EMPIRICAL CONTEXT, METHODS, AND DATA ANALYSIS APPROACH}

\subsection{The empirical context}

We report on a study conducted at one of Saudi Arabia's biggest hospitals, 'CH' in Riyadh. In Saudi Arabia, the Ministry of Health provides $60 \%$ of healthcare services (Altuwaijri, 2008). Free medical care 
is provided to state employees and their families. $\mathrm{CH}$ has 2,000 beds overall and serves around 2,000 outpatient visits a day with a staff of 1,000 .

The focus of this study was the implementation of an EPR system in $\mathrm{CH}$, and more specifically the CPOE module of the system. The EPR includes the ability to input, store and retrieve patient information by medical professionals. It is linked with the radiology department, pharmacy and laboratories. It also makes it possible, through the CPOE module, for physicians to order lab investigations and X-Rays, get the results back, and provide medication alerts and recommended dosages etc. (Berg, 2004, p. 8). As well as seeking to replace paper documentation, the CPOE also specified the best practice protocols for staff to adhere to.

\subsection{Methods and data collections}

Securing access. The research was designed with the aim of providing an in-depth understanding of how EPRs were used within hospital wards. Specifically, we sought to develop an understanding of what people do and what makes sense to them (or not) in specific settings. Access to the hospital was initially established through a family connection one of the authors had to a senior physician in $\mathrm{CH}$. The physician introduced us to the Information Systems Director (ISD). Following preliminary discussions with the ISD, we submitted a formal request to the Hospital Research Committee in writing, detailing our research aims, methods (interviews and observations) and the proposed duration. Approval was granted for 11 months (rather than the requested 12 months), and delays meant effective access was reduced to 9 months. We did not think it sensible to further delay and/or jeopardise access by challenging this. Assurances about data storage and the confidentiality of participants and the hospital itself were also requested. Access was also subject to a sponsor being assigned (the ISD) and a report detailing the overall findings being provided at the end of the research.

The ISD helped secure access to people involved in the implementation of EPR across $\mathrm{CH}$. However, we realised that he was unable to help us to secure access to the detailed practices undertaken at ward level. Thus, we had to fall back on another personal connection, a nursing manager, who drew on her personal relations with the ward managers to ask that they allow us to attend the ward each day and to interview healthcare staff. The nursing manager also enrolled the Director of Nursing, who sent an email memo to all nursing divisions across the hospital. What was apparent from the outset was that the detailed access that we sought was contingent on personal relations and sustaining good will within the wards. 
Phases of the research. The research was conducted primarily in four phases (each lasting 30-60 days) over a nine-month period during which we undertook sustained periods of interviews and observations in the wards. During the breaks between phases, we wrote up the field notes and undertook thematic analysis. Further, due to researcher family commitments it was not practical to be overseas for extended periods. A final follow-up phase of research lasted one month, almost a year after the conclusion of phase three. This enabled us to gain a longitudinal perspective by observing how the relationships between the health practitioners and the EPR/CPOE evolved over time.

Site. The ward was our primary site of interest. We sought to follow the in-depth practices of healthcare professionals as they undertook their work. It was not possible to investigate all 26 wards at $\mathrm{CH}$ and through consultation with the Nursing Informatics Manager, wards 13 and 6 were chosen because of their high usage level of EPR, and ward 18 and 14a for their comparatively low usage. Furthermore, the Intensive Care Unit was chosen since it was the first ward to fully implement CPOE, which was subsequently implemented in most wards.

Focus. In spending time in the ward our interest was initially focused on how technology and practices were linked through acts of improvisation. Focusing on specific improvisational acts helped us to see the heterogeneous and entangled practices of EPR/CPOE 'use.' However, we found that we tended to focus very much on the human actors as the prime movers of action. Given our ontological positioning we also needed to consider how the non-human actors conditioned and enacted the human health practitioners. Importantly, we needed to also spend time observing the flow of practice, rather than depending only on what our interviewees told us. For example, whilst interviewing one of the ICU consultants in his office we asked, "Do you use the EPR system?" He replied, "Yes, it is a useful system and I use it" in a way that implied that it was obvious. When observing him on his rounds, however, he did not seem to be using EPR as much as making use of it. In other words, he relied on the information from EPR - checking CT scans of patients on the system, looking at trends and lab results etc. - but it was a physician who performed tasks on his behalf such as logging in or opening the appropriate interface.

Research tasks. Table 1 indicates who we interviewed, where, and how much time we spent as observers in each of the wards (organised in terms of phases). In the wards, our research focus was on the interactions between the health professionals (as 'mediated' by the EPR), while also always keenly attending to how the actions of non-humans conditioned the possibilities for action of the humans. Patients did not come into focus other than their being "constructed and reconstructed as 
objects of medical discourse that is [often] enacted away from the patients themselves" (Atkinson, 1995, p. ix).

Table 1: Interview and observations (organised according to phases and wards)

\begin{tabular}{|c|c|c|c|}
\hline \multicolumn{4}{|c|}{ Phase One (60 days) } \\
\hline Location & Ward interviews & $\begin{array}{c}\text { Ward } \\
\text { observation }\end{array}$ & $\begin{array}{l}\text { Other meetings or } \\
\text { interviews }\end{array}$ \\
\hline Ward 18 & $\begin{array}{l}4 \text { nurses, } 1 \text { nurse manager, } 1 \text { Dir of Clinical } \\
\text { Nursing }\end{array}$ & 22 hours & $\begin{array}{l}\text { Orientation training } \\
\text { session and } \\
\text { interviews with } 2 \\
\text { nursing informatics } \\
\text { managers, } 1 \text { IT }\end{array}$ \\
\hline \multicolumn{4}{|c|}{ Phase Two (60 days) } \\
\hline ICU & $\begin{array}{l}6 \text { nurses, } 1 \text { nurse manager, } 2 \text { charge nurses, } 3 \\
\text { clinical resource nurses (CRN), } 1 \text { asst nurse } \\
\text { manager, } 1 \text { ICU director, } 5 \text { physicians, } 3 \text { resident } \\
\text { doctors, } 1 \text { pharmacist }\end{array}$ & 90 hours & $\begin{array}{l}\text { CPOE committee } \\
\text { meeting }\end{array}$ \\
\hline Ward 13 & $\begin{array}{l}1 \text { nurse manager, } 1 \text { charge nurse, } 3 \text { nurses, } 2 \\
\text { CRN, } 1 \text { resident doctor }\end{array}$ & 30 hours & $\begin{array}{l}\text { Interviews with } 1 \\
\text { Nursing informatics } \\
\text { manager, } 1 \text { medical } \\
\text { informatics, } 2 \text { quality } \\
\text { management, } 1 \\
\text { radiology }\end{array}$ \\
\hline \multicolumn{4}{|c|}{ Phase Three (60 days) } \\
\hline ICU & 2 CRN, 5 nurses, 2 physicians & 15 hours & $\begin{array}{l}\text { Interview with } 1 \\
\text { nursing informatics }\end{array}$ \\
\hline \multicolumn{4}{|c|}{ Phase Four (90 days) } \\
\hline ICU & $\begin{array}{l}2 \text { nurses, } 2 \text { CRN, } 1 \text { charge nurse, } 1 \text { resident } \\
\text { doctors, } 1 \text { consultant }\end{array}$ & 40 hours & $\begin{array}{l}\text { CPOE meeting and } \\
\text { interview with COPE } \\
\text { 'go live' manager }\end{array}$ \\
\hline Ward 6 & $\begin{array}{l}1 \text { nurse manager, } 2 \text { charge nurses, } 3 \text { nurses, } 3 \\
\text { CRN, } 1 \text { physical therapist }\end{array}$ & 13 hours & \\
\hline Ward $14 a$ & 1 CRN, 2 Nurses, 3 physicians & 20 hours & \\
\hline \multicolumn{4}{|c|}{$\begin{array}{ll}\text { Final Follow-up (30 days) } \\
\end{array}$} \\
\hline ICU & $\begin{array}{l}2 \text { physicians, } 2 \text { nurses, } 3 \text { CRN, } 1 \text { Charge nurse, } 1 \\
\text { anaesthesiologist }\end{array}$ & 15 & $\begin{array}{l}\text { CPOE committee } \\
\text { meeting }\end{array}$ \\
\hline Ward 6 & 1 charge nurse, 1 CRN, 1 nurse & & $\begin{array}{l}\text { Interviews with } 1 \\
\text { CPOE 'go live' } \\
\text { manager, } 1 \text { nursing } \\
\text { informatics manager }\end{array}$ \\
\hline
\end{tabular}

Observing the medical practices in the ward. The majority of staff working in wards were nurses. We attended daily 6.30am shift change meetings because a large number of nurses attended and discussed the issues that had arisen during their shift and that would need monitoring by the next shift. Nurses constitute the most concrete and ever-present feature in any ward. They start and end 
their shifts in the same ward and have a specified desk at the reception area. Physicians, on the other hand, are more nomadic; visiting different wards depending on the different cases under their care. This difference in attachment to the ward and temporality has important consequences for their daily work practices and how they relate to the EPR/CPOE and to each other.

Interviewing and observing. Our interviews were open-ended and unstructured. They were conducted in this manner in order to be as "contextual" as possible in asking nurses and physicians questions about the EPR/CPOE (the explicit aim of the research) and specific incidents, rather than being confined to general and abstract forms of enquiry (Mason, 2002, p. 64). Some interviews were conducted in situ in front of a terminal or at a bedside. These were mostly "informal conversational interviews" based on both pre-interview preparations and "spontaneous" formation of questions in the field, which provided the flexibility to adjust to situations as they arose (Patton, 2002, pp. 342-43). Others were conducted in offices such as the ward's nurse manager's office. We recorded most office interviews, as participants were able to formally consent to recording and the sound quality was better. We often re-played the relevant recordings to get a better feel for the data (nuances of intonation not being included in the transcriptions). Recording discussions that took place on the ward was not practical for several reasons. First, not all of the people at any given moment had consented to be recorded. Second, the discussions that took place might include confidential patient data. Further, as we made recordings on the move or at nursing stations, the background noise would affect their sound quality. Instead, detailed notes were taken during observations on the ward. Here we recorded what people said and how they conducted their work.

The participant observation conducted in $\mathrm{CH}$ involved being neither a pure observer nor an actual participant (Bryman and Bell, 2011, p. 454). For example, staff often mistook researchers for the EPR implementation team and some of the medial staff would occasionally ask us to do something for them, such as getting a file or communicating a message to another colleague. The number of hours spent on each phase varied (see Table 1). Observations of nurses were of their daily tasks, which entailed collecting data to enter into EPR, entering data into the system, entering data into paper files, and assisting physicians with patients and administrative work. We observed daily ward rounds where consultants, junior physicians, residents, pharmacists and nurses assemble to check on the patients. Observation also involved many informal interviews and conversations. We attended CPOE committee meetings where changes were discussed. 


\subsection{Our approach to analysis}

The data we collected can be thought of as 'process data' since it was collected from the organisation in "real time" while recording nuanced data from the particular setting (Langley, 1999: 691-92). This type of data reflects the situated organisational practices as they are enacted and develop and evolve over time, which makes it messy and hard to categorize and analyse. Consequently, the development of themes was an ongoing, iterative and hermeneutic process (Klein and Myers, 1999), which was consolidated at the end of the four phases in a process presented in Table 2 below. In phase 1 we focused on work practices in the wards and the CPOE meetings. From our reading of the literature we were particularly interested in the notion of improvisation. We expected to encounter the implementation of EPR disrupting existing practices, and staff having to improvise to make things work. In phase 2 we broadened our data collection and tried to capture as much of the medical work in the ward as possible. From the extant literature, we were sensitised to look out for practices around medical hierarchy, collaboration, knowledge sharing, social capital, etc. In considering our data and the literature we wanted to make sure that we were keeping our analytical themes open to critical scrutiny (Myers, 1997; Walsham, 2005).

After each phase we would read and reread our fieldnotes (McLeod and Doolin, 2012) and refine our thematic analysis, moving hermeneutically between the literature, our data, and our research interest (EPR/CPOE). This hermeneutic analysis was done by testing our themes against the literature and our data, and through critical debates between the research team. In phase 3 we became particularly interested in professional boundaries. Our data suggested that there was a lot of contestation of boundaries involved when trying to deal with the changes that the CPOE introduced. In phase 4 we focused on the ongoing negotiation of professional boundaries and the role that both the CPOE and paper records play in these ongoing negotiation practices. It was very evident from our data that the recording practices (on paper, notes, EPR/CPOE) functioned not only as records, but also as ways of communicating, sharing knowledge, ordering work, defining roles, and much more besides. In our final follow-up phase, we revaluated (and collected additional data) about our emerging sense of the centrality of medical record-keeping as part of the practices that contest and negotiate professional boundaries. We tested the emerging themes and notions with our interviewees and allowed them to add some nuance to our analysis as it developed.

Given our theoretical and ontological commitments, we focussed our analysis primarily on the level of actors and their intra-actions (Walsham, 2006); more specifically, on the enactment of concrete everyday situated practices in the flow of daily work in the ward. However, we also sought to locate 
our analysis at ward level within hospital-wide institutional level practices (Davidson and Chiasson, 2005; Walsham, 1998). We recognise that these local and institutional level practices are inextricably intertwined (Korpela et al., 2001). On this view, we agree with Hayes and Westrup (2012), who draw on Strathern's (2005) fractal metaphor to argue that while we zoom in and out, it is still the same object that is being observed. Below we illustrate this as we 'zoom in' on the detailed practices of 'the yellow sticker'.

Table 2: The phased development of our analytical themes and focus

\begin{tabular}{|c|c|c|c|}
\hline & Empirical focus & Analytical themes & Rationale \\
\hline Phase 1 & $\begin{array}{l}\text { Work practices in } \\
\text { Wards, CPOE } \\
\text { meetings }\end{array}$ & $\begin{array}{l}\text { Improvisation (from } \\
\text { literature) }\end{array}$ & $\begin{array}{l}\text { Wanted to see how the } \\
\text { implementation of EPR/CPOE forced } \\
\text { changes in work practices and how } \\
\text { hospital staff dealt with it }\end{array}$ \\
\hline Phase 2 & $\begin{array}{l}\text { Medical care } \\
\text { practices in wards, } \\
\text { CPOE meetings }\end{array}$ & $\begin{array}{l}\text { Medical hierarchy, } \\
\text { collaboration, knowledge } \\
\text { sharing, social capital (from } \\
\text { literature and data) }\end{array}$ & $\begin{array}{l}\text { Wanted to see how the disruptions } \\
\text { (and affordances) of EPR/CPOE } \\
\text { change medical practice in the ward } \\
\text { and contrast it with literature }\end{array}$ \\
\hline Phase 3 & $\begin{array}{l}\text { Medical care } \\
\text { practices in wards, } \\
\text { CPOE meetings } \\
\text { (especially medicine } \\
\text { ordering) }\end{array}$ & $\begin{array}{l}\text { Same as the above as well } \\
\text { as professional boundaries } \\
\text { (from data) }\end{array}$ & $\begin{array}{l}\text { Started to see how the CPOE } \\
\text { disrupted professional boundaries } \\
\text { (an issue that is prevalent in most of } \\
\text { the literature) }\end{array}$ \\
\hline Phase 4 & $\begin{array}{l}\text { Medical care } \\
\text { practices in wards, } \\
\text { CPOE meetings } \\
\text { (especially medicine } \\
\text { ordering) }\end{array}$ & $\begin{array}{l}\text { Same as the above as well } \\
\text { as medical record-keeping, } \\
\text { pragmatic negotiations on } \\
\text { the division of labour (from } \\
\text { data) }\end{array}$ & $\begin{array}{l}\text { Realised that the changes in division } \\
\text { of labour (which seemed innocent) } \\
\text { were much more significant than } \\
\text { seems on the surface. Also, the } \\
\text { relationship between EPR and paper } \\
\text { medical records. }\end{array}$ \\
\hline $\begin{array}{l}\text { Final follow- } \\
\text { up }\end{array}$ & $\begin{array}{l}\text { Medical care } \\
\text { practices in wards, } \\
\text { CPOE meetings } \\
\text { (especially division of } \\
\text { labour in record- } \\
\text { keeping) }\end{array}$ & $\begin{array}{l}\text { Same as the above as well } \\
\text { as professional boundaries, } \\
\text { medical record-keeping and } \\
\text { the relationship between } \\
\text { EPR and paper records } \\
\text { (from data) }\end{array}$ & $\begin{array}{l}\text { More detailed focus on changes in } \\
\text { division of labour and how the } \\
\text { EPR/paper boundary (in medical } \\
\text { record-keeping) was used in } \\
\text { negotiating workflow }\end{array}$ \\
\hline This paper & $\begin{array}{l}\text { Negotiations of } \\
\text { division of labour in } \\
\text { the flow of work } \\
\text { practice }\end{array}$ & $\begin{array}{l}\text { The enactment of a } \\
\text { negotiated order and the } \\
\text { role of sociomaterial capital } \\
\text { in this. }\end{array}$ & $\begin{array}{l}\text { Sociomaterial perspective as } \\
\text { fundamental to understand these } \\
\text { negotiating practices }\end{array}$ \\
\hline
\end{tabular}

\section{FINDINGS AND ANALYSIS: CPOE AND THE INTRA-ACTIONAL ORDER OF MEDICAL PRACTICE}

\subsection{The centrality of medical records to medical care practices}

One set of practices that seemed central to all care practices were record-keeping. Specifically, we 
noted the centrality of record making to the enactment of everyday care practices and the complicated relationship between paper records and electronic records (as represented by the EPR system). This centrality of record making (in the enactment of care) was revealed by the fact that both nurses and the physicians would normally tend to consult the medical records immediately on arrival in the ward, often before speaking to other health care professionals or interacting with the patients. It was clear that recording and reviewing patient records were practices at the heart of clinical care, coordination, communication and decision-making, as confirmed by Berg and Winthereik (2004) in their historical analysis of patient records:

The history of patient records, however, demonstrates that the construction and implementation of new record systems should be seen as the building of a network, a process in which both medical practice and the record system are significantly changed. (p.13, emphasis added) 
Medical record-keeping practices varied from capturing vital signs on a piece of tissue paper, to paper forms, to yellow sticker medical alerts, to entry into the EPR/CPOE system (see Figure 1). As we worked

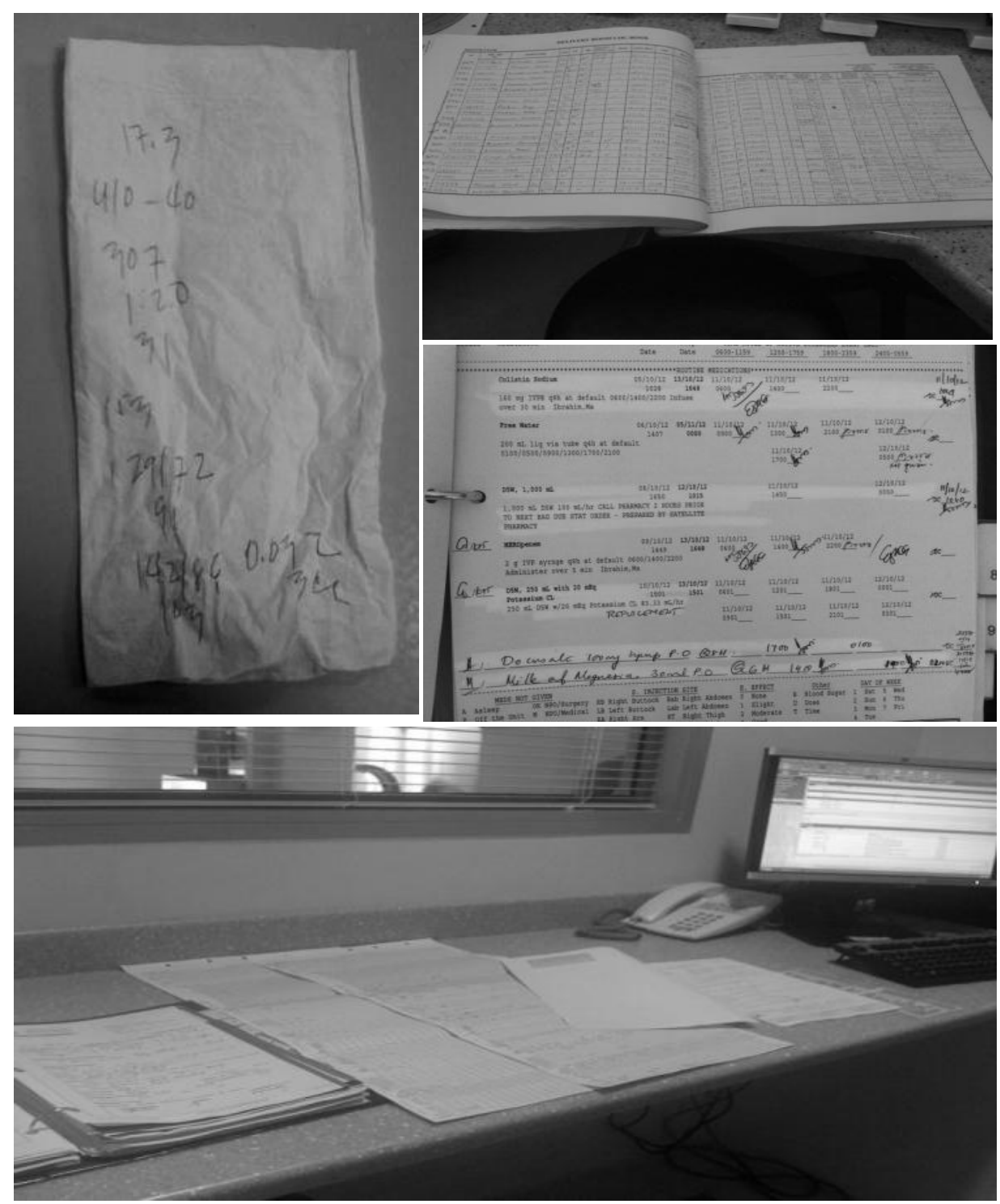

Figure 1: The diverse enactments of the medical record

through the data, we also realised that the nurses and the doctors related to the medical records quite differently. Indeed, they seemed to define themselves (and the patient) in relation to these records. More specifically, the data suggested that the medical record (and record-keeping) might be an important site of intra-actions where the negotiations (which constitute the intra-actional negotiated order) seems to be taking place (as also confirmed by Berg and Winthereik above). 


\subsection{The medical record as an entangled site of ongoing negotiations (initial positioning)}

Our observations in the wards in successive research phases revealed that nurses primarily consider themselves as responsible for the care of patients. They record vital signs, talk to the patients, and administer medicine and treatments. At the ward level, they also provide the continuity of care, weaving diverse temporalities (day and night shift, daily rounds, emergencies, etc.) and diverse professional geographies (doctors, pharmacists, radiologists, etc.) into a seemingly seamless thread of care (Reddy et al, 2001). This means that an important part of the nurses' activity, besides taking care of patients, is to stay on top of medical record requirements such as administering and recording physical assessments, vital signs, lab orders, medications etc. Thus, the nurses' position in the ward and their close relationship with patients makes it their responsibility to ensure that the patient's care trajectory is on track and up to date; as enacted in the medical record. They administer care, under instruction from the physician, and ensure the keeping of records of such care. Indeed, medical records have long been reported as being sites of negotiation between healthcare staff (Berg and Goorman, 1999; Goorman and Berg, 2000; Kaplan, 1995). What this literature and our study highlights is that to care for the medical record is to care for the patient and vice versa-they directly enact each other (Mol, 2003; Berg, 1996).

In contrast, physicians tend to see themselves as autonomous expert professionals (Reddy et al, 2001). They see their contribution as the enactment of appropriate medical expertise that will enable the appropriate medical care to be administered. In short: they are there to diagnose and prescribe and nurses are there to enact such prescription, promptly and correctly. In terms of the division of labour, they tend to consider themselves as the medical experts (the thinkers) and the nurses as the doers of care (Reddy et al, 2001). Nonetheless, in spite, or because of this particular division of labour, doctors and nurses are extremely dependent on each other to ensure the enactment of patient safety and care. What ties them together is the patient, but more concretely, the patient's medical record. By 'medical record', we mean not just one single object but all the records (forms, medicine orders, lab results etc.) that accumulate to form the complete record of care for a particular patient. In many respects, the record is what enacts the patient as a particular patient, with particular conditions, as has been suggested by Berg and Bowker (1997) and by Mol (2003). The nurse administers the medical record and the doctor consults (and authorises) the medical record. The narrative of care between them is also often constructed in relation to, and with, the medical record. In the wards, nurse-doctor interaction often centred around the medical record rather than the patient (prior to CPOE implementation) as the following excerpt reveals: 
While the nurse was entering her vital signs, a physician asked, "Where is the file for 1C?" No one seemed to know, so he stood there waiting for a few minutes. Then he went to the charge nurse asking her directly. She looked around and then said, "Ah the nurse went with the patient to get an ultrasound done" [and took the file with her].

[Doctor] "But I need the file to sign an order. I have an order in there that I have not signed".

[Nurse] "I'll call you when she comes back".

[Doctor] "I won't come back just to sign one order!"

[Nurse] "I cannot carry out the order until you sign"

[Doctor] "I will go there!!"

What did the introduction of CPOE as an actor do when it entered the healthcare practices in the ward? We observed that it disrupted and transformed the current negotiated intra-actional order significantly. The physicians were now expected to enter orders (for lab, medication, radiology, etc.) directly into the CPOE system. Previously, the nurses would have prepared the paperwork for the orders in advance and then merely asked for the doctor's authorisation through a signature (as above). With the implementation of the CPOE system the doctors were not just the authorisers, the source of knowledge, authority and expertise; they also had to enact this knowledge directly through order entry into the CPOE. Historically the division of labour indirectly acknowledged the physician's time as being more valued. Our observations in the wards after CPOE implementation suggested that the doctors would often still ask a nurse to enter orders into the $\mathrm{CPOE}$, and then would check it and submit. The nurse informatics manager suggested that the physicians were having trouble entering orders for themselves because they were "spoiled" by nurses in the past. The physicians' resistance was not just about 'not liking' the system, they simply did not see it as work doctors should be doing. As the ICU consultant explained, for them 'use' means getting the benefit of data/information from the EPR, not 'operating' the system.

Moreover, the physicians were enacted not only as medical experts, but also as novice administrators and error prone. A number of consultants pointed out that one of the disadvantages of 'using' CPOE was "that you might enter the information of one patient into another patient's record." The main problem occurred when previous users of a terminal did not log off and the patient's file was still displayed on the screen. According to nurses, some physicians compounded the problem by picking up a terminal and entering data into CPOE without checking that they had the right patient or even logging on. An ICT consultant confirmed this, noting: 
You go see the screen, you assume that this is the same screen that you have opened a minute ago, you don't look at the name, right? And then you put orders, this happens frequently.

Consequently, some physicians claimed that the EPR was confusing and could cause serious errors, which led them to conclude that the system was neither safe nor useful. The CPOE 'uselessness' was more related to their particular understanding of the appropriate division of labour. It did not make sense to physicians (given their professional positioning) to log in with their own user name and password to access the appropriate patient record, check the top of the screen to verify the name of the patient whenever a new action in the record was required etc. They were expected to exercise new mental tasks of 'looking' and 'orienting' themselves; tasks previously performed by the nurses. These small adjustments to their medical practice due to the new actor (the CPOE) caused uncertainty and discomfort for the physicians: "everyone hates it for multiple reasons" (ICU consultant). This enactment was avoided often by deferring entry of orders: 'I will do it later' (at the end of the round, etc.), was a phrase commonly used by doctors.

Our data suggests that the paper medical record relationally enacted the nurses as expert administrators of care and the doctors as expert authorisers of care. In contrast, the CPOE newly enacted the doctors both as expert authorisers of care, and as novice, error-prone administrators who often delayed care because of the disruptive action of having to enter orders in real time. In line with other studies, the physicians resented the administrative nature of this additional work (Ash et al., 2007; Weiner et al., 1999). The nurses were enacted no longer as expert administrators of care, but rather as an actor correcting the errors and delays produced by the intra-actions of the new CPOE actor: "I prefer to enter these orders myself to get on. Sometimes we wait too long! Especially in the night shift..." (Nurse, ICU). It was also not uncommon for nurses to stand next to doctors and guide them through the screens, pointing out which options to select, and which to ignore. Here is an example from our field notes:

The nurse asked the doctor, "Please change the diet order from NPO to regular". The physician said, "Yes, I can do that - how to do it in the system, that is the problem (laughing) - but I can do it!" He made his way to the terminal and the nurse followed him, asking "Are you okay?" He looked at her and said, "No". She started helping him while he was logged in with his name, giving him instructions on where to go, how to change the order to regular and how to accept the order to finalise it. She then asked him to go back to the order screen (as a sort of test). As he was struggling again, the nurse looked at me saying a bit exasperated, "The doctor is clueless as far as the system is concerned". 
This reconstitutive disruption of the intra-actional order required (or at least called for) some new 'working out' of work arrangements that might re-establish what the actors deem appropriate intraactions; intra-actions that would enact doctors and nurses in ways that they deem meaningful in terms of their own self-understanding of their place within the care practice. In order to understand this renegotiation in more detail we will look more closely at just one specific example: that of medication alerting, a critical aspect of patient care and safety.

\subsection{Medication alerting and intra-action: the story of the yellow sticker (zooming in).}

The case of the 'yellow sticker' provides an interesting empirical site to observe the various actors' attempts to renegotiate the intra-actional order in order to secure their professional identities and interests, as well as their common goal of patient care and safety. The purpose of the yellow sticker produced by the EPR/CPOE system is to warn the medical professionals that a medication currently given to the patient will be automatically discontinued (see example of a redacted yellow sticker in Figure 2).

The implementation of the EPR system allowed for this automatic discontinuation policy to be implemented by the hospital management across all the wards. For example, many antibiotics are due

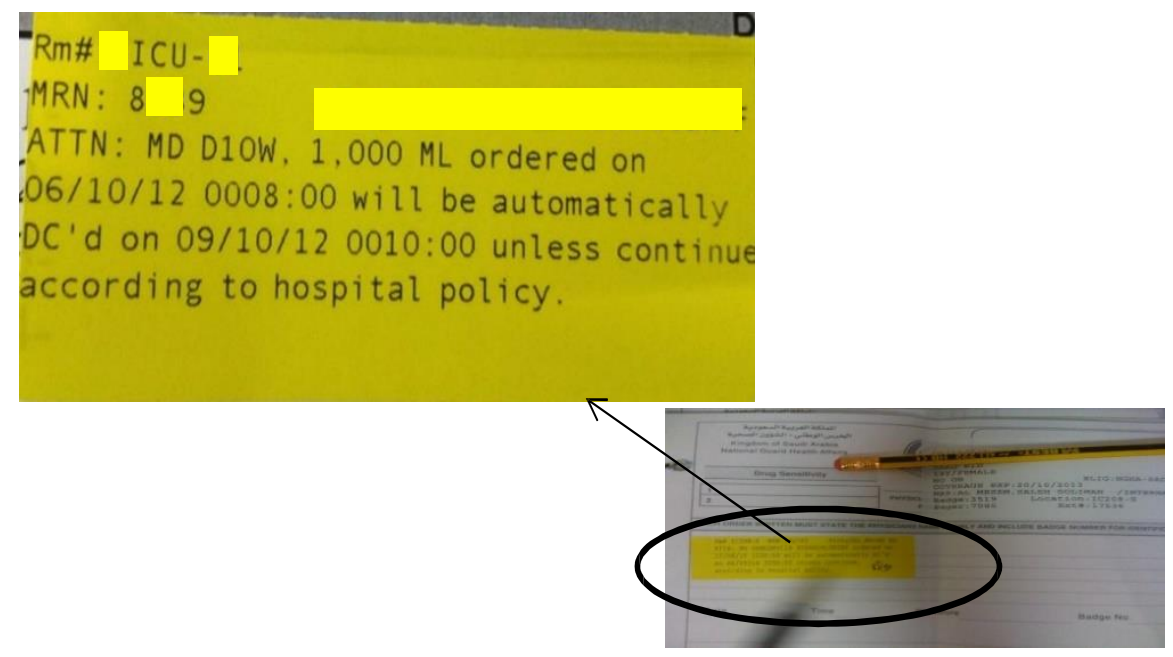

Figure 2: A yellow sticker in the physician order form

for discontinuation after 6 days. The sticker is set as an alerting mechanism to prompt physicians to make a decision on the continuation, or not, of the prescription. The stickers are issued 72 hours before discontinuation and then again 24 hours before. The sticker is printed by the hospital pharmacy from the EPR every day at midnight and distributed to the appropriate wards. If the medication still needs to be given, the physician needs to renew the order in the CPOE to continue the medication. 
Discontinuation would mean that the medication would no longer be dispensed from the pharmacy or appear on the electronic record within the EPR. It would however still be on the paper version of the patient's Medication Administration Record (MAR), which would normally be printed out on a daily basis. The MAR (or eMAR for electronic versions) is the report that serves as a legal record of the medicine administered to a patient within the hospital context. The MAR is part of a patient's permanent medical record and the nurse would sign off on the MAR whenever a drug or device is administered to the patient. Formally, physicians are responsible for keeping track of the medication given to patients. Thus, the yellow sticker primarily addresses the physician. However, its paper form and its location allow it to become an opportunity for the renegotiation of the intra-actional order (and the capital available to the various actors).

Medication procedures are one of the main responsibilities of the physician. However, in practice the nurse checked if there were any yellow stickers for the patient on a particular day. Nurses seemed to accept this task as part of patient medical record-keeping, and crucial to the ongoing care of the patient. Physicians' involvement was usually limited to asking the nurse if there were any yellow stickers for the patient. For the physician, the sticker (as paperwork) addressed the nurse and located the responsibility for reminding the physician with the nurse. The need to 'remind' the physician meant that the physician had to be located, reminded, and then encouraged to enter the renewal order on the CPOE. The charge nurse expressed frustration with this situation: "it is an attitude problem when physicians just don't want to act fast when nurses ask them to enter [orders in the CPOE]". Nurses felt that yellow stickers were a liability, rather than a facilitator, because they had to keep track of them, and remind physicians to follow up on medication orders in the CPOE. Before CPOE implementation, they only had to get doctors' signatures to enact an order. The issue of medication automatic discontinuation was so frustrating to nurses that some of them would pre-empt the yellow sticker:

[During one of the rounds] the nurse reminded the resident (doctor) that the morphine needed to be renewed. He asked, "So there is a yellow sticker?" She said "No but you see it from the date on EPR [CPOE]".

In other words, this nurse checked the date while the doctor was in the ward to ensure the patient would not lose the medication. This meant that they avoided having to search out the doctor on one of the other wards, and having to deal with the consequences if medications were discontinued at the wrong time. 
The question of who was responsible for the alerting of the yellow sticker also played out in terms of where the yellow sticker was physically located. The yellow sticker was located on the Physician Order Form (POF), where physicians previously entered all orders relating to the patient. This location suggested that it was primarily the responsibility of the physician. After the introduction of EPR, physicians were required to enter all the orders, especially medication orders, directly into the CPOE/EPR. As a result, physicians tended not to consult the 'physician order form', and thus the yellow sticker, as part of their patient investigation. When asked why the yellow sticker remained located on the POF the response from nurses and clinical pharmacists were similar:

Nurse 1: Because orders are always located there.

Nurse 2: This is just how things are done.

Clinical pharmacist: Hmm...l don't know why. It's just how they do it.

Also, the Medication Administration Record (MAR), the paper legal record of the medicine administered to a patient, was located on the main nursing desk. The MAR is significant for both nurses and physicians, but particularly for nurses, in terms of creating continuity of care from one shift to another. Nurses review and completed the MAR at the bedside as they administered medication to the patient: they signed the list whenever medication was administered, highlighted medication that had been discontinued, and added any new medications ordered for the patient. The MAR was printed once every 24 hours from the EPR: a temporality similar to the yellow sticker being generated by EPR. Thus, even when the EPR was up to date, nurses had to manually enter any additions or discontinuations on the MAR. The MAR therefore had to be checked to verify that it corresponded with the electronic medication list in the EPR at both shift handovers and when the MAR was reprinted. Physicians also regularly checked the MAR during their ward rounds. Towards the end of the study, we found that the nurses had started to attach yellow stickers to the MAR card. This meant that yellow stickers were no longer located only at the nursing station but were also available to doctors and nurses at the bedside. This not only reduced the chance of physicians missing the yellow sticker, it also provided for opportunities for discussion and knowledge sharing.

\section{DISCUSSION: DISRUPTING/RENEGOTIATING THE NEGOTIATED OR INTRA-ACTIONAL ORDER}

In this section, we will examine how the implementation of a new healthcare technology (a new actor) disrupts the intra-acted negotiated order. We will suggest that the negotiated order can stabilise, however, it can also, at any point, be disrupted through mundane daily work practices, to offer opportunities for renegotiation, implicitly or explicitly (Allen, 1997, 2004; Svensson, 1996). For 
example, the management of $\mathrm{CH}$ wanted to disrupt the current enacted negotiated order, explicitly, to enable the enforcement of certain protocols (e.g. the automatic discontinuation of certain critical medication). The protocol sought to delineate roles in the negotiated order, and in so doing, remove ambiguity in collaborative decision-making and joint work between physicians, nurses and pharmacists. They wanted to locate responsibility in a particular way. Viewed from a sociomaterial perspective, the CPOE is a new actor that disrupted the negotiated order or, as we have suggested, the negotiated intra-actional order. We refer to it as an intra-actional order to attend better to how people and technologies enact each other performatively. We will argue that the negotiated intraactional order was disrupted in four interrelated ways, each offering different renegotiations: of roles, legitimacy, division of labour, and capital.

\subsection{Disrupting/renegotiating subject positions (professional identity)}

To understand the disruption and renegotiation of subject positions (or professional identities) within the intra-actional order, a good place to start is the medical record, and how the nurses and the physicians were enacted in relation to it. As Barad (following Butler) suggests, medical recording practices are the "iterated doing through which subjects come into being." (Barad, 2007, p. 57). A medical record, when current, complete, accurate, etc., enacts the nurse as a valuable member of the care team. Interpreting and developing a diagnosis in relation to the medical record enacts the status of the doctor as a competent clinician. The medical record enacts the patient as normal, abnormal, interesting etc: anomalies in the results or charts can transform the patient from 'just another patient' to a specific case study, requiring specific interventions. In this sense, our findings align with Barley's (1996), as he considers technology as a social object that occasions change and shifts in power relations. Specifically, as sociomaterial actors, we argue that the nurse, the doctor and the patient become enacted, or intra-acted, as very specific subjects in their ongoing intra-action with the medical record. Thus, the medical record is more than a mere representation of the facts (Bowker and Star, 2000; Star and Bowker, 1997). In its intra-action, the medical record with its medical representations (charts, logs, x-rays, etc.) inscribes itself back into the subjects it is supposed to represent i.e. physicians, nurses and patients. Through the intra-actions of the medical record the nurse becomes enacted as a good nurse (or not); the physician as a competent doctor (or not); and the patient as a specific case, with specific conditions, requiring specific interventions (or not). Thus, we see a heterogeneous assemblage of actors co-constituting, or intra-acting each other, as particular subjects. When a new actor emerges, and the medical record becomes 'electronic' and maintained through the CPOE: the doctor becomes enacted as a novice administrator; the nurse as a 'chaser' rather than a competent administrator. What Barad's work does specifically is to help highlight how this 
performative intra-action, in its re-enactment of all implicated actors involved, disrupts longestablished professional boundaries and professional identities, with a potential to delegitimise these actors, both practically and in professional terms. The yellow sticker intra-actively enabled the nurses to re-establish the legitimacy of their caring and coordinating practices. It made them visible once again to physicians and to other staff that might not understand this important role (Reddy et al., 2001). Thus, in its ongoing enactment the patient medical record entangles performatively with the very structure of medical work; as the yellow sticker demonstrates. Different systems of 'recording', or rather enacting the record, embody different ideals of how work ought to be distributed, and such division of labour is critical to ongoing patient care and safety (Reddy et al., 2001).

\subsection{Disrupting/renegotiating legitimacy}

Entering orders directly into the CPOE meant that the legitimacy of the long established division between 'headwork' and 'paperwork' became disrupted. Implicit in the design of the CPOE was the assumed hierarchy of medical expertise. Physicians' knowledge is authoritative and thus they (not nurses) should enter orders to ensure both accuracy and accountability. Yet, this assumed hierarchy was at odds with the already agreed negotiated order operating in the everyday level of the ward. The yellow sticker supposedly spoke to someone, to 'alert' them to the discontinuation of medication by the EPR. The obvious recipient is the physician, since only they can make the relevant decisions about medication for patients under their care. As they must make such prescription orders in the CPOE system, it makes sense to alert them electronically. Yet, the physicians tended to ignore these alerts because for them the alert was meant for the nurses. In their understanding of their own positioning in a medical hierarchy, the nurses were supposed to track medication, alert the doctors, and then prepare the necessary order for them to authorise, by seeking them out for a signature on an order form. Thus, the electronic alerts, addressed to them, do not take account of the medical hierarchy and associated division of labour as established as legitimate in the pre-existing negotiated order. It does not recognise the physicians' positioning, as authoriser, and not administrator.

Enacting this assumed hierarchy of expertise disrupted and delegitimised the long-established practices of the nurses, who had previously sought out signatures from doctors and when doing so, had ensured all medications, investigations etc. were planned in good time. This reduced their ability to influence doctors and thus ensure that things were in place for a patient. Delegitimising the nurses' practices thus could lead to negative outcomes such as misunderstandings, delays and medical errors (Aarts et al., 2007). However, mostly physicians tended to delegitimise the intra-action of the CPOE system, by delegating the entry task to nurses, avoiding it, and being critical of the CPOE. In other 
words, they attempted to delegitimise the CPOE that enacted them in a particular way, in order to maintain the pre-existing division of labour and professional boundaries between doctors and nurses. The yellow sticker created the conditions of possibility for a partial renegotiation, but also facilitated the ongoing legitimacy of the CPOE.

\subsection{Disrupting/renegotiating collaboration}

The disruption of medical work and the incorporation of the new actor also had implications for collaboration between healthcare professionals. The literature highlighted that medical knowledge is collaborative and distributed (Wears and Berg, 2005). However, we found that the CPOE reinforced a view of medical practice as being individualised and hierarchical (Berg, 1997). However, the printing of a yellow sticker transforms the order entry task back into paperwork, and in so doing recognises that doctors and nurses accomplish work jointly between them (Xiao et al, 2001). This is because the nurses doing the paperwork, for and in support of physicians, creates opportunities for interaction and knowledge transfer through inter-professional collaboration around medically significant decisions (Gorman et al., 2003). The yellow sticker, as a non-human actor, re-enacts a particular division of labour; restoring, but also subtly transforming the opportunities for collaboration. The yellow sticker intra-acts the physician as the location of expertise, who needs to be alerted and supported to enact appropriate medical knowledge. But it also does more. It transforms the physician, as the one who has to enter the order on $\mathrm{CPOE}$, as being co-responsible for medical administration. Thus, it restores and redistributes the division of labour in different ways.

Reddy et al (2001) highlight that in hospital settings physical proximity is important for the coordination of group work. The yellow sticker, moreover, represents an important place of intraaction (Østerlund, 2008). The printed yellow sticker aligns itself with the power relations, norms and cultural understandings that condition medical work ( $\varnothing$ sterlund, 2008). The paper based yellow sticker provides for the coordination of in-depth medical work in the wards: it aligns with the "important spatio-temporal rhythms, meanings, practices, and artefacts" of day-to-day interactions between healthcare professionals ( $\varnothing$ sterlund, 2008: 220). Thus, seemingly mundane practices and artefacts (such as forms, yellow stickers, and order entry) can have significant ontological implications (of being and action) that are important to understanding what actors actually do, as the heterogeneous order becomes renegotiated, continually. 


\subsection{Disrupting/renegotiating social (material) capital}

In this final section of the discussion, we argue that social capital played an important role in the disrupting and reestablishment of the negotiated order. Specifically, we consider how the EPR and the yellow sticker were implicated in this as non-human actors. Leonardi et al. (2013: 11) define social capital as typically referring to "the actionable resources accumulated through the relationships among people." Central to such understandings is the notion that capital is, or actionable resources are enacted through, social relations; i.e. it is the outcome of relationality. Social capital, as actionable resources, is both medium and outcome of ongoing relationality (Lin, 2004). If the enactment of social relations change, the actionable resources also change, more or less significantly. Thus, what we want to highlight, given our ontological commitments, is that capital, as actionable resources, is not only a 'structural' feature but rather also something mundane that becomes enacted relationally in and through mundane everyday work practices. Doctors and nurses act to maintain, extend and regain their actionable resources through their situated and ongoing work practices. We would suggest therefore that the ongoing enactment of available actionable resources (or capital) is at the heart of the ongoing relational constitution of the negotiated order.

What our sociomateriality perspective suggests is that in the ongoing intra-action the EPR and the yellow sticker are also central to the ongoing accomplishment of the actionable resources available to human actors, because social capital is more accurately expressed as sociomaterial capital. The entry of the EPR into the relational work practices disrupted the actionable resources available to doctors and nurses in their ongoing negotiation of the intra-actional order, transforming their ability to enact their professional identity and interests. For example, the total reliance on the EPR for making most medical orders, and nurses therefore no longer being able to enter physicians' orders, meant that access to the EPR transferred certain actionable resources from nurses to doctors, and asserted their expertise and authority. Institutional practices enhanced this potential by conferring legitimacy on the EPR, by positioning it as a very significant actor (for modernisation, efficiency, accreditations etc.). Drawing on these resources, however, disrupted certain traditional professional boundaries and identities. For doctors, unfamiliar with the mundane tasks of medical record-keeping, the ERP did not become actionable resources to assert their status and expertise, but resources of inaction, often delegated. Loss of access to medical record-keeping practices removed certain actionable resources from nurses, leaving them unable to assert aspects of their medical care expertise such as identifying faults and reminding doctors. Again, this disrupted a negotiated order in which both professional groups could negotiate boundaries and the division of labour in ways commensurate with their understandings of themselves as professionals. 
The yellow sticker, as a flexible paper-based 'portable place' ( $\varnothing$ sterlund, 2008), entered medical care practices and created the conditions of possibility for both groups to re-position professional boundaries and associated identities. In drawing on the possibilities, it offered in a variety of ways, the doctors were (re)positioned as expert physicians and the nurses as collaborators and expert administrators. Thus, a mundane 'add on' created to enforce institutional policy became a major new sociomaterial actor (or capital) that reconstituted the network of available resources and offered the possibilities to reorder work practices in accordance with the understanding of the various actors involved.

What our analysis reveals is that restricting our considerations to human actors, when considering capital or available actionable resources, fails to attend to the role of materiality in relationally enacted social capital: what we refer to as sociomaterial capital. Such a view would suggest that it is more appropriate to refer to the way the CPOE disrupted and offered opportunities for renegotiation, relationally, as the (re)enactment of sociomaterial capital. What this suggests is that focussing on the situated and ongoing relational enactment of sociomaterial capital avoids seeing capital and associated agency as being located in actors, whether human or non-human. Moreover, in using the notion of sociomaterial capital we become aware of how certain opportunities for the (re)enactment of capital is distributed in mundane practices, and also that these mundane sociomaterial work practices (of recording, reading, printing etc) allow for the enactment of capital in a situated and contingent manner.

\section{CONCLUDING REMARKS}

To conclude, this paper has sought to extend ideas on the negotiated order through the conceptual vocabulary of sociomateriality. What we have argued is that most, if not all of the literature on the negotiated order has tended to privilege the (re)negotiating actions of humans over and above the actions of non-humans. It treats non-humans mostly as tools or scenery within, or through, which humans structure their work practices, in ongoing negotiated accomplishments. We have shown that (as Latour would say) by returning the missing masses, we can understand the negotiated order instead as the negotiated intra-actional order. Significantly, this is not merely a change in how we describe things. Changes in situated mundane work practices have ontological implications: all actors are concretely and actually what relational heterogeneous sociomaterial practices enact them to be. Such practices transform the 'who' that they are becoming, and therefore what becomes possible to do (or not), as this or that sort of actor. This insight has important implications for how we think of 'implementation,' for example. 
Traditionally, we might have seen the actions of doctors and nurses as 'resisting' the changes that the implementation of the CPOE brought about, and we might therefore have created pressure points or incentives for them to change their practices; assuming that their actions are expressions of their intentions, motivations etc. From the perspective of an intra-actional negotiated order we appreciate that they are enacted through the actions of CPOE as actors that they do not recognise themselves to be, and that this actor-positioning delegitimises their work, works against collaboration, and is ultimately potentially unsafe. They will tend to use contingent and situated opportunities (such as the yellow sticker) to relationally renegotiate (more or less successfully) their positioning within the relational network: to be and act differently, and presumably more appropriately. Importantly, this is not just 'clever' workarounds, it is rather matter, mattering (Barad, 2007). It is about matter, a yellow sticker, creating the conditions of possibility for a particular way of understanding the world (and how to be in it appropriately) to become concretely possible. Nevertheless, this is not a well thought-out plan. Rather, it is done through contingent, situated and mundane work practices as they emerge and unfold, the stuff of daily work rather than the systems, policies, and procedures that supposedly defines work, structures, and our roles in it (as business process reengineering often suggests). Taking this perspective offers a more nuanced approach to change and transformation; one that recognises all the heterogeneous actors involved and their ongoing positions, and appreciates the contingent and ontological nature of change. Specifically, it reveals the contingent and fragile nature of the negotiated intra-actional order, evident in our case in several ways. The CPOE's protocol encapsulated ideals for how different healthcare professionals ought to perform their work, and how responsibilities and work should flow between them. Similarly, the yellow sticker was not merely a reminder note for healthcare professionals. Rather, through the actions of the CPOE and the yellow stickers, they became enacted differently. These actors (re)negotiated the relations between doctors and nurses, firstly disrupting (and then restoring) their subject positions, legitimacy, collaborative work etc. They established a relational, renegotiated order in which all actors act and are enacted contingently and continuously to accomplish what work is becoming, as everyday work.

Furthermore, social capital defined as relationally enacted and available actionable resources is sociomaterial capital, bringing all actors (not only humans) into play. Sociomaterial capital provides us with an understanding of how the mundane material world of 'tools' and 'systems' provide ontological landscapes that shape and are being shaped through ongoing negotiations. In this landscape a 'yellow sticker' is as important as a doctor or a nurse in understanding what daily work is becoming in the flow of practice. In its positioning, the yellow sticker is powerful enough to produce a different kind of nurse and doctor, showing us how matter matters, as Barad claims. 
Of course, our paper only follows the actions of a small number of actors and we do not want to claim too much, nor too little. However, what we want to do is to encourage those who study and implement information systems to refrain from attributing agency to human or non-humans alone (as such) and rather to appreciate the contingent and situated drama of everyday (re)negotiation, in which seemingly small changes can have significant ontological implications, for being and acting, for the actors implicated. Finally, we would encourage future studies to consolidate, expand and critique the conceptual contours of the notions of the negotiated intra-actional order and sociomaterial capital we have developed here. We see them as open and ongoing questions to be interrogated, theoretically and practically.

\section{REFERENCES}

Aarts J, Ash J and Berg M (2007) Extending the understanding of computerized physician order entry: Implications for professional collaboration, workflow and quality of care. International Journal of Medical Informatics 76(1). Information Technology in Health Care: Sociotechnical ApproachesITHC 2004: S4-S13. DOI: 10.1016/j.ijmedinf.2006.05.009.

Allen D (1997) The nursing-medical boundary: a negotiated order. Sociology of Health and illness 19(4): 498-520.

Allen D (2004) Re-reading nursing and re-writing practice: towards an empirically based reformulation of the nursing mandate. Nursing Inquiry 11(4): 271-283. DOI: 10.1111/j.14401800.2004.00234.x.

Alter S (2014) Theory of Workarounds. Communications of the Association for Information Systems 34(1). Available at: http://aisel.aisnet.org/cais/vol34/iss1/55.

Altuwaijri M (2008) Electronic-Health in Saudi Arabia. Just around the Corner? Saudi Medical Journal 29(2): 171-178.

Ash JS, Sittig DF, Poon EG, et al. (2007) The extent and importance of unintended consequences related to computerized provider order entry. Journal of the American Medical Informatics Association: JAMIA 14(4): 415-423. DOI: 10.1197/jamia.M2373.

Barad K (2003) Posthumanist Performativity: Toward an Understanding of How Matter Comes to Matter. Signs 28(3): 801-831.

Barley SR (1986) Technology as an Occasion for Structuring: Evidence from Observations of CT Scanners and the Social Order of Radiology Departments. Administrative Science Quarterly 31(1): 78. DOI: $10.2307 / 2392767$.

Barrett M, Oborn E, Orlikowski WJ, et al. (2012) Reconfiguring Boundary Relations: Robotic Innovations in Pharmacy Work. Organization Science 23(5): 1448-1466. DOI: 10.1287/orsc.1100.0639. 
Berg M (1996) Practices of reading and writing: the constitutive role of the patient record in medical work. Sociology of health \& illness 18(4): 499-524.

Berg M and Bowker G (1997) The Multiple Bodies of the Medical Record. Sociological Quarterly 38(3): 513-537. DOI: 10.1111/j.1533-8525.1997.tb00490.x.

Berg $M$ and Goorman E (1999) The contextual nature of medical information. International Journal of Medical Informatics 56(1): 51-60. DOI: 10.1016/S1386-5056(99)00041-6.

Berg M and Winthereik BR (2004) Waiting for Godot: episodes from the history of patient records. In: Berg M (ed.) Health Information Management: Integrating Information Technology in Health Care Work. London \& New York: Routledge, pp. 11-44.

Beuscart-Zéphir MC, Pelayo S, Anceaux F, et al. (2005) Impact of CPOE on doctor-nurse cooperation for the medication ordering and administration process. International Journal of Medical Informatics 74(7-8): 629-641. DOI: 10.1016/j.ijmedinf.2005.01.004.

Bowker GC and Star SL (2000) Sorting Things Out: Classification and Its Consequences. Cambridge (Massachusetts); London: MIT Press.

Cecez-Kecmanovic D, Kautz K and Abrahall R (2014) Reframing Success and Failure of Information Systems: A Performative Perspective. MIS Quarterly 38(2): 561-588. DOI: 10.25300/MISQ/2014/38.2.11.

Cheng $\mathrm{CH}$, Goldstein MK, Geller E, et al. (2003) The effects of CPOE on ICU workflow: an observational study. In: AMIA Symposium Proceedings, 2003, pp. 150-154. Available at: https://www.researchgate.net/profile/Raymond_Levitt/publication/8915883_The_effects_o f_CPOE_on_ICU_workflow_An_observational_study/links/548881300cf289302e30b22f.pdf (accessed 16 February 2017).

Christensen LR (2016) On Intertext in Chemotherapy: an Ethnography of Text in Medical Practice. Computer Supported Cooperative Work (CSCW) 25(1): 1-38. DOI: 10.1007/s10606-015-92381.

Davidson E and Chiasson M (2005) Contextual influences on technology use mediation: a comparative analysis of electronic medical record systems. European Journal of Information Systems 14(1): 6-18. DOI: 10.1057/palgrave.ejis.3000518.

Debono DS, Greenfield D, Travaglia JF, et al. (2013) Nurses' workarounds in acute healthcare settings: a scoping review. BMC health services research 13: 175. DOI: 10.1186/1472-6963-13-175.

Escobar-Rodríguez T and Romero-Alonso M (2014) The acceptance of information technology innovations in hospitals: differences between early and late adopters. Behaviour \& Information Technology 33(11): 1231-1243. DOI: 10.1080/0144929X.2013.810779.

Fitzpatrick G and Ellingsen G (2013) A Review of 25 Years of CSCW Research in Healthcare: Contributions, Challenges and Future Agendas. Computer Supported Cooperative Work (CSCW) 22(4-6): 609-665. DOI: 10.1007/s10606-012-9168-0. 
Flanagan ME, Saleem JJ, Millitello LG, et al. (2013) Paper- and computer-based workarounds to electronic health record use at three benchmark institutions. Journal of the American Medical Informatics Association 20(e1): e59-e66. DOI: 10.1136/amiajnl-2012-000982.

Goffman E (1983) The Interaction Order: American Sociological Association, 1982 Presidential Address. American Sociological Review 48(1): 1-17. DOI: 10.2307/2095141.

Goorman E and Berg M (2000) Modelling nursing activities: electronic patient records and their discontents. Nursing Inquiry 7(1): 3-9. DOI: 10.1046/j.1440-1800.2000.00053.x.

Gorman PN, Lavelle MB and Ash JS (2003) Order creation and communication in healthcare. Methods of Information in Medicine 42(4): 376-384.

Halbesleben JRB, Savage GT, Wakefield DS, et al. (2010) Rework and workarounds in nurse medication administration process: implications for work processes and patient safety. Health Care Management Review 35(2): 124-133. DOI: 10.1097/HMR.0b013e3181d116c2.

Hayes N and Westrup C (2012) Context and the processes of ICT for development. Information and Organization 22(1): 23-36. DOI: 10.1016/j.infoandorg.2011.10.001.

Hsu C, Lin Y-T and Wang T (2015) A legitimacy challenge of a cross-cultural interorganizational information system. European Journal of Information Systems 24(3): 278-294.

Hultin L and Introna L (2018) On Receiving Asylum Seekers: Identity working as a process of materialdiscursive interpellation. Organization Studies: 26.

Introna LD (2013) Epilogue: Performativity and the becoming of sociomaterial assemblages. In: de Vaujany F-X and Mitev N (eds) Materiality and Space: Organizations, Artefacts and Practices. Houndmills, Basingstoke, Hampshire [England]; New York: Palgrave Macmillan, pp. 330-342.

Introna LD and Hayes N (2011) On sociomaterial imbrications: What plagiarism detection systems reveal and why it matters. Information and Organization 21(2): 107-122.

Kaganer E, Pawlowski SD and Wiley-Patton S (2010) Building Legitimacy for IT Innovations: The Case of Computerized Physician Order Entry Systems*. Journal of the Association for Information Systems; Atlanta 11(1): 1-33.

Kaplan B (1995) Information Technology and Three Studies of Clinical Work. SIGBIO Newsl. 15(2): 25. DOI: $10.1145 / 216200.216204$.

Klein HK and Myers MD (1999) A Set of Principles for Conducting and Evaluating Interpretive Field Studies in Information Systems. MIS Quarterly 23(1): 67-93. DOI: 10.2307/249410.

Korpela M, Mursu A and Soriyan HA (2001) Two Times Four Integrative Levels of Analysis: A Framework. In: Russo NL, Fitzgerald B, and DeGross JI (eds) Realigning Research and Practice in Information Systems Development: The Social and Organizational Perspective. IFIP - The International Federation for Information Processing. Boston, MA: Springer US, pp. 367-377. DOI: 10.1007/978-0-387-35489-7_24. 
Langley A (1999) Strategies for Theorizing from Process Data. The Academy of Management Review 24(4): 691-710. DOI: 10.2307/259349.

Latour B (1992) Where Are the Missing Masses? The Sociology of a Few Mundane Artifacts. In: Shaping Technology/Building Society: Studies in Sociotechnical Change. Cambridge (Massachusetts); London: MIT Press, pp. 225-258.

Leonardi PM, Huysman M and Steinfield C (2013) Enterprise Social Media: Definition, History, and Prospects for the Study of Social Technologies in Organizations. Journal of ComputerMediated Communication 19(1): 1-19. DOI: 10.1111/jcc4.12029.

Li W, Liu K, Yang H, et al. (2014) Integrated clinical pathway management for medical quality improvement - based on a semiotically inspired systems architecture. European Journal of Information Systems 23(4): 400-417. DOI: 10.1057/ejis.2013.9.

Lin N (2004) Social Capital: A Theory of Social Structure and Action. Cambridge \& New York: Cambridge University Press.

McLeod L and Doolin B (2012) Information systems development as situated socio-technical change: a process approach. European Journal of Information Systems 21(2): 176-191. DOI: 10.1057/ejis.2011.43.

Menon S, Murphy DR, Singh H, et al. (2016) Workarounds and Test Results Follow-up in Electronic Health Record-Based Primary Care. Applied Clinical Informatics 7(2): 543-559. DOI: 10.4338/ACl-2015-10-RA-0135.

Mol A (2003) The Body Multiple: Ontology in Medical Practice. Durham: Duke University Press.

Mouzelis N (1992) The Interaction Order and the Micro-Macro Distinction. Sociological Theory 10(1): 122-128. DOI: 10.2307/202026.

Myers MD (1997) Critical Ethnography in Information Systems. In: Lee AS, Liebenau J, and DeGross JI (eds) Information Systems and Qualitative Research: Proceedings of the IFIP TC8 WG 8.2 International Conference on Information Systems and Qualitative Research, 31st May-3rd June 1997, Philadelphia, Pennsylvania, USA. IFIP - The International Federation for Information Processing. Boston, MA: Springer US, pp. 276-300. DOI: 10.1007/978-0-38735309-8_15.

Orlikowski WJ and Scott SV (2008) Sociomateriality: Challenging the Separation of Technology, Work and Organization. The Academy of Management Annals 2(1): 433-474. DOI: 10.1080/19416520802211644.

Orlikowski WJ and Scott SV (2013) What Happens When Evaluation Goes Online? Exploring Apparatuses of Valuation in the Travel Sector. Organization Science 25(3): 868-891. DOI: 10.1287/orsc.2013.0877.

$\varnothing$ sterlund CS (2008) Documents in Place: Demarcating Places for Collaboration in Healthcare Settings. Computer Supported Cooperative Work (CSCW) 17(2): 195-225. DOI: 10.1007/s10606-0079064-1. 
Petrakaki D, Waring J and Barber N (2014) Technological affordances of risk and blame: the case of the electronic prescription service in England. Sociology of Health \& Illness 36(5): 703-718. DOI: $10.1111 / 1467-9566.12098$.

Rack LL, Dudjak LA and Wolf GA (2012) Study of nurse workarounds in a hospital using bar code medication administration system. Journal of Nursing Care Quality 27(3): 232-239. DOI: 10.1097/NCQ.0b013e318240a854.

Reddy MC, Dourish P and Pratt W (2001) Coordinating Heterogeneous Work: Information and Representation in Medical Care. In: Prinz W, Jarke M, Rogers Y, et al. (eds) ECSCW 2001: Proceedings of the Seventh European Conference on Computer Supported Cooperative Work 16-20 September 2001, Bonn, Germany. Dordrecht: Springer Netherlands, pp. 239-258. DOI: 10.1007/0-306-48019-0_13.

Saginur M, Graham ID, Forster AJ, et al. (2008) The uptake of technologies designed to influence medication safety in Canadian hospitals. Journal of Evaluation in Clinical Practice 14(1): 2735. DOI: 10.1111/j.1365-2753.2007.00780.x.

Scott SV and Orlikowski WJ (2014) Entanglements in Practice: Performing Anonymity Through Social Media. MIS Quarterly 38(3): 873-893. DOI: 10.25300/MISQ/2014/38.3.11.

Star SL and Bowker GC (1997) Of Lungs and Lungers: The Classified Story of Tuberculosis. Mind, Culture, and Activity 4(1): 3-23. DOI: 10.1207/s15327884mca0401_2.

Strathern M (2005) Partial Connections. Updated edition. Walnut Creek Lanham New York Toronto Oxford: AltaMira Press.

Strauss A and Corbin J (1998) Basics of Qualitative Research: Techniques and Procedures for Developing Grounded Theory. second edition. Thousand Oaks u.a.: SAGE Publications, Inc.

Strauss AL (1978) Negotiations: Varieties, Contexts, Processes, and Social Order. San Francisco, Calif: Jossey-Bass.

Svensson R (1996) The interplay between doctors and nurses-a negotiated order perspective. Sociology of Health \& IIIness 18(3): 379-398. DOI: 10.1111/1467-9566.ep10934735.

Tsai H, Compeau D and Meister D (2017) Voluntary use of information technology: an analysis and synthesis of the literature. Journal of Information Technology 32(2): 147-162. DOI: 10.1057/jit.2016.6.

Van Der Sijs H, Rootjes I and Aarts J (2011) The shift in workarounds upon implementation of computerized physician order entry. Studies in Health Technology and Informatics 169: 290294.

Walsham G (1998) IT and changing professional identity: Micro-studies and macro-theory. Journal of the American Society for Information Science 49(12): 1081-1089. DOI: 10.1002/(SICI)10974571(1998)49:12<1081::AID-ASI4>3.0.CO;2-R. 
Walsham G (2005) Critical engagement: why, what and how? In: Howcroft D and Trauth EM (eds) Handbook of Critical Information Systems Research: Theory and Application. Cheltenham, UK: Edward Elgar Publishing, pp. 225-243.

Walsham G (2006) Doing interpretive research. European Journal of Information Systems 15(3): 320330. DOI: 10.1057/palgrave.ejis.3000589.

Warholak TL and Rupp MT (2009) Analysis of community chain pharmacists' interventions on electronic prescriptions. Journal of the American Pharmacists Association 49(1): 59-64. DOI: 10.1331/JAPhA.2009.08013.

Wears RL and Berg M (2005) Computer Technology and Clinical Work: Still Waiting for Godot. JAMA 293(10): 1261-1263. DOI: 10.1001/jama.293.10.1261.

Weiner M, Gress T, Thiemann DR, et al. (1999) Contrasting Views of Physicians and Nurses about an Inpatient Computer-based Provider Order-entry System. Journal of the American Medical Informatics Association 6(3): 234-244. DOI: 10.1136/jamia.1999.0060234.

Zhou X, Ackerman M and Zheng K (2011) CPOE workarounds, boundary objects, and assemblages. In: CHI '11 Proceedings of the SIGCHI Conference on Human Factors in Computing Systems, Vancouver, 2011, p. 3353. ACM Press. DOI: 10.1145/1978942.1979439. 